\title{
Interações entre organizações coletivas na promoção do desenvolvimento local
}

\section{Interactions between collective organizations in the promotion of local development
Interactions entre des organisations collectives dans la promotion du développement local

Interacciones entre las organizaciones colectivas en la promoción del desarrollo local

\author{
Alair Ferreira de Freitas* \\ alairufv@yahoo.com.br \\ Alan Ferreira de Freitas* \\ freitasalan@yahoo.com.br
}

Recebido em 06/08/2012; revisado e aprovado em 28/10/2012; aceito em 20/12/2012

\begin{abstract}
Resumo: Este artigo buscou compreender como a criação de um arranjo organizacional cooperativo pode contribuir para o fortalecimento de organizações da agricultura familiar, especialmente da Cooperativa de Crédito da Agricultura Familiar e Economia Solidária (Ecosol), e imprimir um caráter específico à dinâmica do desenvolvimento local sustentável em Espera Feliz, Minas Gerais. Os resultados mostram que as interações sociais estabelecidas entre as organizações locais e a cooperativa tornaram-se um meio prático de fazer da racionalidade econômica um instrumento de fortalecimento do cooperativismo e de desenvolvimento local.
\end{abstract}

Palavras-chave: Interação social. Cooperativa de Crédito Solidária. Cooperação.

Abstract: This article aimed to understand how the creation of a cooperative organizational arrangement may contribute to the strengthening of family farming organizations, especially the Cooperativa de Crédito da Agricultura Familiar e Economia Solidária (Ecosol), and print a special character to the dynamics of local development on Espera Feliz, Minas Gerais. The results show that social interactions established between local organizations and the cooperative became a practical means of making the economic rationality of an instrument of strengthening cooperatives and local development.

Key words: Social interaction. Credit Union Solidarity. Cooperation.

Résumé: Cet article vise à comprendre comment la création d'un accord de coopération de l'organisation peut contribuer au renforcement des organisations de l'agriculture familiale, en particulier de la Cooperativa de Crédito da Agricultura Familiar e Economia Solidária (Ecosol), et d'imprimer un caractère spécial à la dynamique de développement local en Espera Feliz, Minas Gerais. Les résultats montrent que les interactions sociales pactisées entre les organisations locales et la coopérative se sont rendues demi praticien de faire de la rationalité économique un instrument de fortification du coopératisme et de développement local.

Mots-clés: Interaction sociale. Coopérative de Crédit Solidaire. Coopération.

Resumen: Este artículo tiene como objetivo entender cómo la creación de una forma organizativa cooperativa puede contribuir al fortalecimiento de las organizaciones de agricultura familiar, especialmente de la Cooperativa de Crédito da Agricultura Familiar e Economia Solidária (Ecosol), e imprimir un carácter especial a la dinámica de desarrollo local en Espera Feliz, Minas Gerais. Los resultados demuestran que las interacciones sociales establecidas entre las organizaciones locales y la cooperativa se habían convertido en una manera práctica hacer de la racionalidad económica un instrumento del fortalecimento del cooperativismo y del desarrollo local.

Palabras clave: Interacción social. Cooperativa Del Crédito Solidary. Cooperación.

\section{Introdução}

O desenvolvimento não é um resultado automático do crescimento econômico. Deriva das relações humanas, do desejo, da vontade, das escolhas que as pessoas podem fazer para alcançar melhores condições de vida. O desenvolvimento é produzido pelas pessoas, é orientado pelas necessidades e aspirações dos atores e, por isso, podemos dizer, é socialmente construído. Ademais, a indução dos processos de desenvolvimento é provocada pela capacidade desses atores em articular as potencialidades locais às oportunidades externas para viabilizar iniciativas inovadoras e fortalecer as ações coletivas em curso (BUARQUE, 2002), ou seja, para transformar os atributos e oportunidades naturais em vantagens competitivas para a promoção do desenvolvimento.

Nessa discussão sobre o desenvolvimento, o conceito de local não está atrelado somente à definição de um determinado espaço geográfico, mas compreende a constituição do tecido social em que permeiam as relações entre os indivíduos e organizações.

* Universidade Federal de Viçosa (UFV), Viçosa, MG, Brasil. 
O local é uma referência socioespacial de operacionalização das ações de promoção do desenvolvimento.

Quando o debate sobre o desenvolvimento é aplicado ao meio rural, podem-se destacar as abordagens sobre a agricultura familiar, segmento que historicamente esteve alijado das políticas públicas e da ação do Estado em geral. O termo agricultura familiar designa uma diversidade de atores que têm em comum a ligação com o campo por meio de alguma atividade agrícola, com a utilização dos recursos naturais de que dispõe, e o emprego de mão de obra familiar. Estes se diferenciam de várias maneiras, como o nível de renda, a forma como exploram os recursos, os tipos de atividades, tradições, entre outras, além de diferenciarem-se de acordo com a região onde está inserida sua propriedade. Assim o ambiente físico, geográfico e cultural que circunda a unidade familiar rural intervém diretamente na sua forma de organização e na construção da identidade dos agricultores (MDA, 2007).

A agricultura familiar, abrangendo diversas formas de organização e reprodução socioeconômicas, consolida-se não apenas como um segmento econômico, mas também como um modo de vida estreitamente ligado à realidade local na qual as propriedades que a compõem se encontram. Essa realidade local e o próprio segmento da agricultura familiar não são estáticos. Esse conjunto de atores, práticas e processos inseridos na dinâmica das unidades familiares rurais vem passando por transformações técnicas e econômicas. Essas transformações estão estreitamente ligadas às próprias mudanças sociais e organizativas dos agricultores e às evoluções do ambiente institucional, principalmente ligadas às políticas de desenvolvimento rural, que incidem diretamente nas práticas econômicas e organizacionais desse segmento (SABOURIN, 2006).

Essas mudanças na agricultura familiar, ligadas às novas formas de governança do desenvolvimento rural no Brasil, induzem as organizações de agricultores familiares a assumirem novos papéis. Elas são mobilizadas em particular, em dois tipos de circunstâncias: i) para assumir funções de interesse geral que eram antes da responsabilidade do Estado ou que deveriam sê-lo, ii) para participar da elaboração ou da gestão de projetos ou programas de desenvolvimento local, territorial ou de manejo de recursos naturais (SABOURIN, 2006). Isto é observado principalmente a partir de novos discursos acompanhando as tendências das políticas públicas que incentivam a organização formal da agricultura familiar e o desenvolvimento rural sustentável.

Nas abordagens contemporâneas sobre o desenvolvimento rural, o crédito é um elemento considerado estratégico (ABRAMOVAY, 2004). Contudo é necessário que ele esteja acessível ao público que realmente o demanda e que, com mais frequência, necessita dele. A operacionalização do crédito ao público de baixa renda é feita através de instituições financeiras. As cooperativas de crédito, sendo autorizadas pelo Banco Central do Brasil (Órgão de regulamentação do setor financeiro) como tal, são apontadas como um instrumento de referência na operacionalização do crédito a populações de baixa renda (CAZELLA; BÜRIGO, 2009). Essas organizações se distinguem por se constituírem enquanto sociedade de pessoas e não de capital, cujos clientes são também seus proprietários.

A reprodução social das famílias rurais de baixa renda perpassa pelo acesso ao crédito. Isso diz respeito à obtenção de alguma forma de crédito (como empréstimos informais com agiotas) ou, mais comumente, modalidade de poupanças informais para se garantir contra imprevistos (como a manutenção de um animal para ser vendido em caso de doença na família). Mais que um setor, as finanças informais podem representar a própria rede de relações sociais de que dependem os indivíduos e as famílias pobres (ABRAMOVAY, 2004).

Os laços financeiros, nesse sentido, podem ser muito mais ricos que a impessoalidade expressa nos serviços bancários formais, pois edificam-se sobre o contato frequente com o fornecedor do crédito e a fidelidade entre ambos agentes. É o que Búrigo (2006) caracteriza como relações de proximidade nos serviços financeiros. Constata-se, com efeito, que a exclusão financeira está associada à baixa presença de organizações financeiras locais que conheçam melhor as necessidades de seus clientes e se orientem pela lógica da 
solidariedade, diferente de agiotas (serviços informais) e de bancos (serviços formais). Sob esse contexto, as cooperativas aparecem como importante ator social para suprir a necessidade de acesso ao crédito adequado à realidade da agricultura familiar e a promoção do desenvolvimento local. As cooperativas de crédito rural podem se integrar em arranjos organizacionais cooperativos, em que as diversas organizações locais se beneficiam mutuamente.

Assume-se aqui a premissa de que as formas e práticas organizacionais são condicionadas pela sua imersão na estrutura social, pois, de acordo com Granovetter (1985), fatores socioculturais exercem papel significativo no desempenho de organizações, e a ação econômica, por sua vez, está imersa em relações sociais, pelas quais são moldadas.

Com base na experiência recente do sistema Ecosol de Cooperativas de Crédito da Agricultura Familiar e Economia Solidária no estado de Minas Gerais, mais especificamente a cooperativa Ecosol Zona da Mata e Leste de Minas e sua atuação no município de Espera Feliz, procurou-se compreender como a criação de um arranjo organizacional cooperativo pode contribuir para o fortalecimento de organizações da agricultura familiar, em especial para a cooperativa de crédito, e imprimir um caráter específico à dinâmica do desenvolvimento local sustentável. O que buscamos identificar, portanto, não são indicadores de desenvolvimento em si, mas as propriedades que caracterizam a alimentação recíproca entre um arranjo organizacional e o contexto social local. Faz-se importante esse recorte analítico por permitir evidenciar as relações interorganizacionais que dinamizam a operacionalização dos serviços financeiros e a vida econômica dos agricultores e suas famílias no processo de desenvolvimento local.

Para apresentar os resultados da pesquisa e as questões suscitadas, o texto apresenta-se dividido em cinco seções além desta introdução. Na próxima seção, evidenciam-se os pressupostos teóricos utilizados para a compreensão da atuação das cooperativas de crédito solidárias e suas relações com outras organizações de agricultores familiares. $\mathrm{Na}$ terceira seção, apresentam-se os aspectos metodológicos da pesquisa. Na quarta, são apresentados resultados e discussão, infor- mando sobre o sistema Ecosol e sua atuação em Minas Gerais e a dinâmica do arranjo organizacional da agricultura familiar do qual faz parte. Para finalizar, são apresentadas algumas considerações finais.

\section{Pressupostos teóricos}

Para entender a atuação das cooperativas, as relações interorganizacionais e o acesso de populações de baixa renda a serviços financeiros formais, a economia não pode ser analisada como uma esfera autônoma da vida social (POLANYI, 2000). Sob o referencial da Sociologia Econômica, parte-se do pressuposto de que os comportamentos e instituições são tão condicionados pelas relações sociais, que conceituá-los como independentes e atomizados representa um sério equívoco (GRANOVETTER, 1985). Apropriar dessa lente para analisar as organizações e suas relações pode permitir transcender um tipo de abordagem racionalista e formalista, direcionando o percurso analítico para as interações sociais e as dinâmicas organizacionais que caracterizam processos de desenvolvimento local.

Ao analisar as ações econômicas sob a luz das estruturas sociais, Granovetter (1985) conclui que, mesmo na sociedade capitalista, o comportamento econômico encontra-se enraizado em redes sociais. As relações sociais são entendidas aqui como o "[...] comportamento reciprocamente referido quanto a seu conteúdo de sentido por uma pluralidade de agentes e que se orienta por essa referência" (WEBER, 1991, p. 228). Essas relações passam a condicionar as formas de atuação e interação estabelecidas entre os atores e projetam, para além de uma racionalidade estritamente econômica, seus fins e meios à consecução de objetivos comuns.

A confiança, a cooperação e a reciprocidade reproduzidos pelas relações sociais são mecanismos amplamente presentes nas organizações e condicionam a forma como elas coordenam as interações com clientes, fornecedores, parceiros, Estado, comunidade, investidores, inclusive concorrentes (SACOMANO NETO; TRUZZI, 2008). Evidenciar esses elementos é considerar a existência de um capital social que compõe o substrato das organizações. 
A literatura que trata do surgimento do conceito de capital social atribui a Bourdieu (1986) e Coleman (1988) o pioneirismo no tratamento deste. São autores que influenciaram significativamente os estudos, por exemplo, de Robert Putnam. Putnam (1996) considera que o capital social é constituído por elementos das organizações sociais (redes, normas e confiança) que facilitam a ação e a cooperação para benefício mútuo, uma vez que um acervo abundante de capital social proporciona um trabalho em conjunto mais fácil.

O capital social pode ser definido como: [...] "as características das redes de relações sociais, como confiança, normas e sistemas, que contribuam para aumentar a eficiência da sociedade, facilitando as ações coordenadas" (PUTNAM, 1996, p. 177). Conceitualmente esse autor define a noção de capital social em relação à capacidade dos grupos e organizações que formam a sociedade civil em prol do desenvolvimento do trabalho coletivo no alcance de objetivos comuns, geradores de maior eficiência na produção coletiva de outros tipos de capitais (econômico, financeiro, político etc.). O capital social é um instrumento importante para compreender como as redes sociais e organizacionais contribuem para o desenvolvimento das cooperativas e das localidades onde atuam.

As redes sociais, conceito importante para compreender as relações sociais sob uma perspectiva estrutural, permitem conferir sentido e operacionalizar a ideia de enraizamento social do comportamento econômico (embeddedness, como conceituou Granovetter (1985)). As redes sociais podem ser entendidas como formas de interação social que permitem a diferentes atores interatuarem entre si, provocando o contato e a constituição de relações duradouras. Rede social é um instrumento que permite descrever e analisar as interações entre os indivíduos, as relações interorganizacionais e intraorganizacionais (STEINER, 2006).

Os vínculos constituídos a partir das redes podem resultar em relações de confiança, desde que realimentados por reciprocidade, elemento essencial para a manutenção das interações e de oportunidades coletivas a partir das organizações que lhe fazem parte. Contudo as redes sociais não são garantias de eficiência nas atividades econômicas. Para favorecer essas atividades, é fundamental que a rede apresente características que lhe confiram vantagens competitivas (por exemplo, redução dos custos de transação e da assimetria de informação) e se tornem um capital social orientador da regulação econômica e da atuação dos atores.

Em se tratando das cooperativas de crédito solidárias, esses pressupostos teóricos são importantes para potencializar a compreensão da formação e atuação de organizações financeiras que lidam cotidianamente com um público de baixa renda. Essas organizações necessitam desenvolver estratégias para manutenção de suas relações com o mercado, com parceiros e com o Estado, as quais são decisivas sobre sua capacidade operacional e impactam na reprodução social das famílias pobres a elas associadas.

Como observou Granovetter (2001), a existência de ligações estreitas entre as instituições de financiamento e as redes de produção e comercialização possibilita inovações organizacionais que podem levar mais facilmente ao sucesso dos pequenos negócios. Percebe-se, assim, a importância de estabelecer arranjos locais e parcerias institucionais entre organizações financeiras, como as cooperativas de crédito solidárias, e redes de produção e comercialização, como as cooperativas e associações de agricultores familiares. Isso pode articular as redes sociais às ações econômicas empreendidas pelos atores locais e formar capital social, substrato preponderante para a consolidação desse tipo de organização e para a promoção do desenvolvimento local.

\section{Aspectos metodológicos}

Optou-se por realizar uma pesquisa de abordagem qualitativa e de caráter exploratório, especialmente diante da novidade que representam essas organizações em Minas Gerais e a complexidade que traduzem em sua existência. Devido à falta de estudos anteriores sobre a experiência desse tipo de cooperativa de crédito em Minas Gerais, utilizou-se do estudo de caso como estratégia de pesquisa, analisando o caso particular do município de Espera Feliz, MG. Várias são as definições encontradas para o estudo de caso, mas a mais recorrente é a de Yin (2001), que 
afirma que o estudo de caso é uma pesquisa empírica em que se estuda um acontecimento contemporâneo, dentro de um contexto da vida real. $\mathrm{O}$ autor ressalta ainda que tal metodologia é importante por permitir uma reflexão aprofundada do fenômeno em particular e a identificação de outros fenômenos ligados à história dos atores sociais.

A etapa de coleta de dados foi realizada em agosto e setembro de 2010. Os dados secundários foram adquiridos por meio de pesquisa documental, baseada em relatórios e formulários, principalmente o Estatuto Social, o Regimento Interno e Relatórios de Planejamento. Os dados primários foram coletados a partir de entrevistas semiestruturadas. Foram realizadas entrevistas com o diretor geral, o diretor financeiro e a funcionária do Posto de Atendimento Cooperativo da Ecosol em Espera Feliz, e dois diretores do Sindicato de Trabalhadores Rurais, todos são cooperados e membros de outras organizações locais, totalizando cinco (5) entrevistas em profundidade. Foram realizadas também conversas informais com diretores de todas as organizações locais, devidamente registradas em um caderno de campo, instrumento de pesquisa que possibilitou registro das falas dos informantes e as percepções do pesquisador. Portanto a amostra é intencional e não probabilística, selecionando informantes qualificados ligados à trajetória da cooperativa e das organizações locais (sindicatos, cooperativa agrária e associação de agricultores), prezando pela riqueza e profundidades das informações, e não por um quantitativo de entrevistados.

A observação participante também foi utilizada, de modo a obter uma melhor compreensão dos acontecimentos e da dinâmica relacional, sendo observadas reuniões da cooperativa de crédito, da cooperativa agrária e do sindicato de trabalhadores rurais, tendo destaque o planejamento do sistema Ecosol em Minas Gerais, no qual estavam presentes representantes das organizações locais da agricultura familiar. Todas as observações e conversas informais durante as reuniões foram devidamente registradas no caderno de campo.

Após a coleta, a próxima etapa foi de organização e análise dos dados, realizada através da técnica de análise de conteúdo
(BARDIN, 2009). Nesta etapa os dados foram decompostos de suas fontes originais para, em seguida, serem reorganizados com o fim de melhor expressar sua significação. Essa reorganização buscou recortar o conteúdo seguindo uma proximidade de sentido, contendo fragmentos do discurso e ideias temáticas de formação das categorias analíticas que orientaram as análises que se seguirão. Isso se iniciou com a transcrição e leitura dos dados e seu agrupamento de acordo com os objetivos da pesquisa. Após a sistematização dos dados, se procedeu a uma análise sistemática, relacionando e confrontando os dados primários aos secundários, buscando a sua interpretação à luz do referencial estruturado anteriormente e das questões que orientaram a pesquisa.

\section{Resultados e discussão}

a) As cooperativas de crédito rural solidárias em Minas Gerais

O sistema Ecosol é um exemplo do cooperativismo de crédito solidário, reunindo cooperativas de crédito rural em âmbito nacional no Brasil. Em Minas Gerais o sistema concentra-se na Zona da Mata Mineira. Ele surge por iniciativa da Central Única dos Trabalhadores (CUT) através de uma política de fomento ao crédito para trabalhadores, implementada por sua Agência de Desenvolvimento Solidário (ADS). Em parceria com sindicatos de todo o Brasil, a ADS iniciou um processo de constituição de uma Central de Crédito, formada por cooperativas de crédito sem vinculação a outro sistema ou descontentes com os sistemas aos quais estavam vinculadas. As cooperativas eram discutidas sob o princípio da solidariedade e o modelo de autogestão, buscando nova lógica para a organização e para os serviços financeiros no atendimento de um público até então excluído do escopo dos bancos.

As cooperativas do sistema Ecosol em MG surgiram como consequência de uma série de mobilizações sociais, iniciadas em 2002, como desdobramento do movimento político da agricultura familiar, conduzidas principalmente pelos Sindicatos de Trabalhadores Rurais. As experiências de crédito rotativo desenvolvidas na região com o 
apoio da Organização Não-Governamental (ONG) Centro de Tecnologias Alternativas da Zona da Mata Mineira (CTA/ZM) antecederam as cooperativas e se tornaram fator relevante para sua constituição. Passados aproximadamente dois anos de mobilizações e experiências, foram formalizadas duas cooperativas em MG: uma no município de Araponga (Ecosol Araponga), em novembro de 2004, e outra no município de Tombos (Ecosol Zona da Mata e Leste de Minas), em fevereiro de 2005. Após a constituição dessas cooperativas, criou-se uma base de serviços da Ecosol em MG, (com formato legal de uma associação), como forma de apoiar e dar assistência técnica ao sistema, sobretudo em relação à contabilidade, controles internos, formação dos associados e dirigentes, softwares e relações com bancos, governo e outras entidades.

Em MG ainda permanecem apenas duas cooperativas, mas a cooperativa sediada em Tombos se expandiu no ano subsequente de sua formação e criou Postos de Atendimento ao Cooperado nos municípios de Espera Feliz, Simonésia e Divino. Já a cooperativa de Araponga é restrita ao município de Araponga. Os cooperados dessas cooperativas são todos agricultores familiares, em sua maioria parceiros e meeiros com propriedade de dois alqueires em média. A maioria dos sócios é associada a outras organizações locais, destacando os sindicatos, cooperativa agrária, associação de produtores e associações comunitárias.

Em seu processo de desenvolvimento, o sistema Ecosol em MG tem se mostrado eficiente para lidar com capital próprio e, após as cooperativas terem cumprido todas as metas exigidas pelo Banco Central ${ }^{1}$, apresentam uma considerável evolução em termos de carteira de empréstimos, capital social e o quadro social. No caso da cooperativa Ecosol em Espera Feliz, objeto de análise deste trabalho, isso pode ser mais bem visualizado a partir da Tabela 1:

Tabela 1 - Indicadores de desempenho financeiro do PAC Ecosol Espera Feliz em dezembro de 2010.

\begin{tabular}{lc}
\hline \multicolumn{1}{c}{ Indicadores } & PAC Ecosol - Espera Feliz \\
\hline N. sócios & 340 \\
Capital social & $\mathrm{R} \$ 44.383,00$ \\
Carteira de Empréstimos & $\mathrm{R} \$ 97.394,00$ \\
Depósitos a prazo (poupança e aplicação) & $\mathrm{R} \$ 120.209,00$ \\
Patrimônio Líquido Ajustado & $\mathrm{R} \$ 61.509,13$ \\
\hline
\end{tabular}

Fonte: Dados da pesquisa.

A situação expressa acima também é fruto de parcerias e articulações. Os indicadores financeiros expressos na Tabela são formados apenas por capital próprio, tendo em vista que as cooperativas não acessam recursos públicos ou fundos privados externos ao quadro social. Os expressivos valores estão ligados ao adensamento das parcerias locais, reforçando as redes organizacionais existentes em sua área de atuação, assim como analisaremos a seguir. b) Caracterização do arranjo organizacional da agricultura familiar em Espera Feliz

Em Minas Gerais, a população rural passou de $71 \%$ em 1950 para apenas $18 \%$ da população total em 2000, com a expulsão do campo de grandes contingentes de agricultores sem condições de competir e se reproduzir socialmente na ordem econômica instalada. Especificamente no município de Espera Feliz, a população rural compreende aproximadamente $45 \%$ do total de habitantes,

\footnotetext{
${ }^{1}$ O Banco Central exige metas de crescimento econômico nos cinco primeiros anos de funcionamento de uma cooperativa de crédito. No final do quinto ano é necessário ter $\mathrm{R} \$ 60.000,00$ em capital social.
} 
sendo a população total de aproximadamente 21.000 habitantes segundo o Instituto Brasileiro de Geografia e Estatística (IBGE, 2009)². Entre a população rural, a maioria são agricultores familiares, tendo uma participação importante na economia do município. Essa breve caracterização ressalta a importância de estudos que tomem a população rural como foco. Apesar do êxodo rural, a grande parcela de habitantes na área rural indica a relevância que pode representar as cooperativas para esse setor especificamente, principalmente quando se considera a agricultura familiar.

Em Espera Feliz, as experiências político-religiosas de base comunitária, historicamente alicerçadas na agricultura familiar, se concretizaram em um plano de desenvolvimento local denominado Envolvimento Local (ELO). Trata-se de um plano de ação iniciado em 2004, que promoveu várias discussões e funcionava sob a forma de um colegiado, composto por várias organizações representativas dos trabalhadores rurais, tais como Sindicato dos Trabalhadores Rurais (STR), Associação Intermunicipal da Agricultura Familiar (Asimaf), Grupo de Mulheres (GM), Pastoral da Juventude Rural (PJR), Cooperativa de Produção da Agricultura Familiar e Solidária (Coofeliz), Cooperativa de Crédito da Agricultura Familiar e Economia Solidária (Ecosol), Associação dos Terapeutas homeopatas (Teravida) e o Centro de Tecnologias Alternativas da Zona da Mata (CTA/ZM), ONG sediada em Viçosa, MG. O ELO buscava a melhoria das condições de vida a partir da utilização de recursos locais e da mobilização das próprias pessoas na solução de seus problemas. Para isso, valorizou-se a formação dos jovens, a participação das mulheres, o fortalecimento das organizações coletivas e o envolvimento das comunidades na elaboração e execução de ações que poderiam superar os problemas e proporcionar melhor qualidade de vida à população rural.

É a partir desse programa (ELO) que acontece a constituição de algumas organizações coletivas (como as cooperativas de crédito e de produção: Ecosol e a Coofeliz, respectivamente) e que se intensificam as interações entre as organizações locais de agricul-

\footnotetext{
${ }^{2}$ Dados extraídos do site http://www.ibge.gov.br/ cidadesat/topwindow.htm?1 em 10/07/2010.
}

tores familiares do município de Espera Feliz. A interação entre as organizações, tanto na elaboração e execução dos planejamentos do sistema Ecosol em MG, quanto na integração a ações e projetos comuns, vão desenhando os contornos do arranjo organizacional em que se insere a Ecosol Zona da Mata e Leste de MG em Espera Feliz ${ }^{3}$.

Para melhor visualizar a estrutura do arranjo que envolve a Ecosol, segue abaixo um esboço através da Figura 1. Deixamos claro que as relações e formas de interação estabelecidas entre a Ecosol e os atores externos, (como os bancos e universidades) também são de suma relevância para a sustentabilidade da cooperativa e a promoção do desenvolvimento local. Porém, nos concentramos neste estudo nas relações a nível local entre a Ecosol e as organizações da agricultura familiar de Espera Feliz, pois são estas que mantêm relações muito próximas e cotidianas com a cooperativa de crédito:

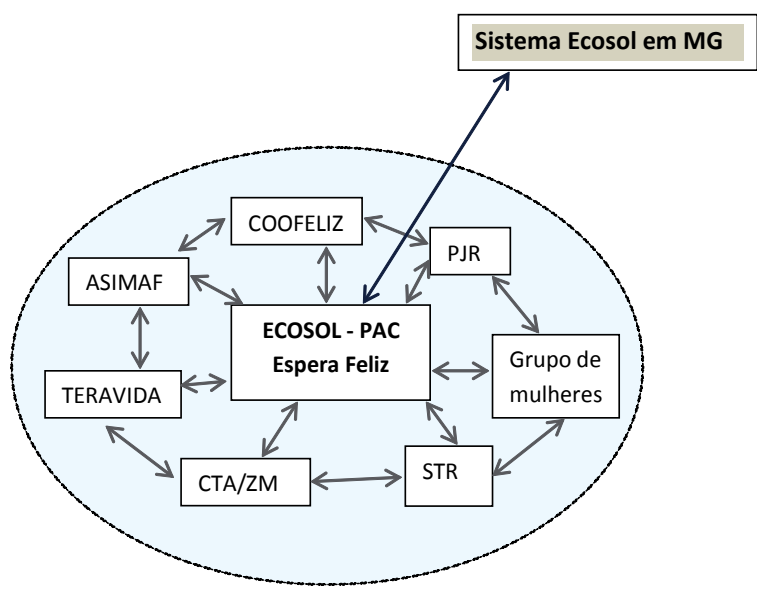

Figura 1 - Arranjo organizacional da agricultura familiar a partir da Ecosol em Espera Feliz.

Nesse arranjo, a Ecosol estabelece parcerias concretas com as demais organizações locais de agricultores familiares, pois estão envolvidas no mesmo contexto, sob os mesmos referenciais sociopolíticos. Isso a permite também desenvolver mecanismos de controle social do crédito, aproveitando as potencialidades das organizações de base, como o trabalho efetivo nas comunidades, o conhecimento entre seus membros e as relações de parentesco que circunscrevem sua

\footnotetext{
${ }^{3}$ A partir de agora, vamos denominar essa cooperativa apenas como Ecosol para simplificar.
} 
atuação para dinamizar as relações financeiras. Esse arranjo redimensiona a atuação das organizações locais e consequentemente da Ecosol, pois amplia sua capilaridade ao atuarem conjuntamente, sob agendas comuns, em espaços comuns de interação.

Nesse caso, vale destacar o Sindicato de Trabalhadores Rurais (STR) de Espera Feliz, que atua há muitos anos na região em que está presente a Ecosol. A valorização das formas com que o sindicato organiza suas bases sociais, através de núcleos formados por comunidades rurais, facilita a inserção e circulação de informações sobre a cooperativa, seus produtos e serviços, e a obtenção de informações sobre os associados e as respectivas demandas pelo crédito. Isto acontece na maioria das vezes por meio dos agentes de crédito e desenvolvimento ${ }^{4}$, que também fazem parte do STR e permitem intensificar relações de maior proximidade com os associados, flexibilizando assim os critérios para a concessão e acompanhamento dos investimentos captados pela cooperativa. De acordo com Magalhães (2004), a proximidade como marca de um arranjo organizacional amplia os processos de aprendizado e inovação, que conferem novas vantagens competitivas aos empreendimentos. A cooperação pode ampliar também o acesso a mercados e reduzir custos de transação nas atividades comerciais.

O STR ainda contribui na mobilização e no incentivo de seus sócios para a filiação à Ecosol, pois estimula a atividade produtiva baseados nos princípio da agroecologia ${ }^{5}$, dentro de um projeto político compartilhado também pela Ecosol. O crédito é concebido aí como um instrumento para o fortalecimento da agricultura familiar e de indução de processos de desenvolvimento local sustentável.

Outra organização importante nesse arranjo é a Associação Intermunicipal da Agricultura Familiar (Asimaf), responsável pela or-

\footnotetext{
${ }^{4}$ Os agentes de crédito e desenvolvimento são pessoas físicas responsáveis por mobilizar diretamente nas comunidades os sócios da Ecosol, além de atuarem na divulgação e captação de informações para a cooperativa.

${ }^{5}$ Para Altieri (1999) a agroecologia é uma ciência, um conjunto de conceitos, princípios e métodos que permitem estudar, manejar e avaliar um ecossistema agrícola, oferecendo diretrizes para uma agricultura sustentável, ambientalmente sadia, socialmente justa e economicamente viável.
}

ganização política dos agricultores familiares, capacitação e captação de recursos, buscando a dinamização dos processos produtivos da agricultura familiar. Essa organização, na busca pelo fortalecimento das atividades produtivas de seus sócios, seja através de projetos de financiamento ou pela prestação de assessoria e intercâmbios, fortalece também a demanda pelo crédito, pois gera oportunidades atrativas em que se criam demandas legítimas pelo crédito. Essas demandas, como muitas vezes não são satisfeitas pelos intermediários convencionais (bancos e agiotas), necessitam de crédito para seu desenvolvimento ou ficarão à beira da liquidação de seus ativos produtivos, arriscando-se numa operação onerosa ou de alto risco, endividando-se (GONZÁLESVEGA, 2000).

Contudo essa parceria com a Ecosol possibilita acesso qualitativo a ativos produtivos em condições especialmente referenciadas pelo seu contexto específico, ou seja, a cooperativa disponibiliza o crédito necessário para investimento nas oportunidades reais, $\mathrm{e}$ a baixo custo $^{6}$, através de um serviço personalizado e desburocratizado. Os investimentos, de acordo com as orientações da Ecosol e da Asimaf, devem destinar-se a atividades produtivas sustentáveis, baseadas na agroecologia, assim como é também apoiado pelo STR.

Para exercer a atividade de comercialização, foi criada em 2005, como desdobramento das atividades da Asimaf, a cooperativa de produção da agricultura familiar solidária de Espera Feliz (Coofeliz). Seu papel fundamental é a organização da produção e comercialização da diversidade de produtos da agricultura familiar de Espera Feliz. Os trabalhos de base realizados pela Coofeliz também são fundamentais para a Ecosol na medida em que possibilitam maior capilaridade das suas ações e capacita os agricultores para a ação cooperativa. Essas duas organizações também compartilham de projetos políticos, orientando o formato organizacional e

\footnotetext{
${ }^{6}$ Segundo os dados da pesquisa e os relatos dos entrevistados, os custos do empréstimo através da Ecosol chegam a ser cerca de $50 \%$ mais baixos em determinados produtos que nos intermediários convencionais. Naqueles produtos em que o custo é equiparado, a Ecosol diferencia-se pela facilidade de acesso (não baseando em bens patrimoniais como forma de aval) e condição de pagamento (flexibilizando o total de parcelas e o tempo de carência).
} 
o conteúdo de suas atuações pela Economia Solidária. Parcerias econômicas também são estabelecidas entre essas organizações, como no caso de processos de comercialização, principalmente para mercados institucionais, em que a Ecosol realiza empréstimos à Coofeliz para que ela efetue o pagamento dos cooperados rapidamente após a entrega de seus produtos e, quando a comercialização for realizada e os pagamentos concluídos para a Coofeliz, esta devolve o empréstimo a Ecosol com os juros devidos.

A Associação dos Terapeutas Homeopatas (Teravida) trabalha no município com o tratamento homeopático de homens, mulheres, animais e lavouras. Boa parte do movimento político da agricultura familiar de Espera Feliz ${ }^{7}$ compartilha com essas orientações, principalmente porque buscam não utilizar produtos químicos nas lavouras e rebanhos. Em suas orientações, a Teravida também busca a autonomia dos agricultores familiares, por isso o crédito da Ecosol é concebido em contraposição ao crédito dos bancos, que prestam serviços impessoais a taxas de juros exorbitantes. Ainda, se preocupa em orientar os investimentos da transição agroecológica por meio da Ecosol e reforçam a sustentabilidade e a harmonia com o meio ambiente junto aos agricultores.

A Pastoral da Juventude Rural (PJR) e o Grupo de Mulheres (GM) também são parceiras da Ecosol e fazem parte do arranjo organizacional em destaque. $\mathrm{O}$ trabalho com jovens da PJR, principalmente através da "Escolinha Sindical" 8 , desencadeia uma série de consequências como a inserção de jovens na diretoria das organizações locais e a manutenção de grande parte no meio rural. O GM mobiliza agricultoras familiares para ações políticas e econômicas, como a produção de artesanato para geração de renda. Em

\footnotetext{
${ }^{7}$ Quando mencionado "movimento político da agricultura familiar" quer-se dizer sobre os agricultores familiares vinculados ao STR e demais organizações locais, oriundas de uma trajetória política marcante de luta por direitos e organização política dos trabalhadores rurais do município.

${ }^{8}$ Espaço de formação política de jovens filhos de agricultores familiares conduzido pelo STR em parceria com outras organizações. As oficinas oferecidas pela escolinha são ministradas por membros do sindicato e das organizações parceiras, que contribuem com temáticas relacionadas às suas práticas.
}

parceria com a Ecosol, essas organizações concebem um uso especial ao dinheiro em relação à aplicação feita pelos homens adultos e, portanto, a cooperativa lança novas linhas de crédito, direcionados aos jovens e as mulheres, com taxas de juros também especiais, mais baixas que outros produtos e serviços. Foi notado que os homens adultos utilizam o empréstimo basicamente para investimentos produtivos em suas propriedades, e a renda destinada a mulheres e jovens vinha desses investimentos, sendo realocados para uso familiar. Com essas novas modalidades de crédito, direcionadas a esses grupos, as mulheres (artesanato) e jovens (apicultura) investem em empreendimentos, cujo retorno é usado de forma diferenciada do dinheiro recebido pelos investimentos produtivos dos homens adultos.

O Centro de Tecnologias Alternativas da Zona da Mata (CTA/ZM) é uma Organização Não Governamental sediada em Viçosa, que vem contribuindo com as atividades produtivas dos sócios da Ecosol, pois disponibiliza assessoria à organização dos agricultores e a seus investimentos produtivos na orientação da transição agroecológica. O acompanhamento proporciona melhores direcionamentos à produção, que visam gerar maior rentabilidade e oportunidade a investimentos futuros. Vale destacar que o CTA/ZMnão promove um acompanhamento sistemático aos cooperados da Ecosol, mas desenvolve ações de formação e educação que orientam a prática agroecológica e que contribuem para a difusão de informações e para a mobilização de agricultores sobre esse escopo de ação.

\section{c) Análise do arranjo organizacional da agricultura familiar em Espera Feliz}

Essas relações vistas a partir de uma organização focal possuem sempre algo em comum, que tece identidades coletivas e culturas organizacionais específicas: orientações ideológicas que expressam o viés político das organizações sobre uma proposta de intervenção na realidade. A agroecologia, no fortalecimento de uma matriz tecnológica alternativa, e a Economia Solidária, como uma nova proposta de organização não capitalista do trabalho, da produção e da comercializa- 
ção, são princípios convergentes nesse arranjo organizacional.

Uma das maiores dificuldades enfrentadas pela Ecosol nesse cenário é a coordenação das ações a partir da rede de organizações da qual dependem para a manutenção de um ambiente institucional e social adequado à sua sustentabilidade. O estímulo ao fortalecimento de relações de proximidade e confiança necessário à cooperativa é provocado pela organização de "sistemas locais de governança" (MAGALHÃES, 2004). A formação desses sistemas de governança, no caso da Ecosol/ MG, é decorrente de um processo complexo, consequência de um aprendizado coletivo em torno de mecanismos de coordenação de ações que visam não somente ao crescimento estrutural da organização, mas à formação de um capital social na promoção do desenvolvimento local sustentável.

Outra estratégia de interação é a renovação constante dos espaços institucionais de participação, integrando as organizações locais nos processos decisórios da Ecosol (como no caso dos planejamentos estratégicos da cooperativa), o que promove a relação de confiança entre as partes. Como assinala Gambetta (1988), confiança e interação promovem condições favoráveis à honestidade e à cooperação, gerando assim uma economia sadia, e a reputação de ser confiável que produz essa interação social se reforça mutuamente num benéfico concerto de interesses.

Pode-se perceber que as ações desencadeadas no bojo desse arranjo, a partir das interações entre as organizações locais, fundamentam-se em uma concepção de sustentabilidade por seguir preponderantemente a construção de atividades produtivas ligadas a agroecologia, práticas culturais e sociais de base comunitária, valorizando o conhecimento do sistema de valores e crenças dos atores, e atividades econômicas baseadas na solidariedade em detrimento da racionalidade econômica estrita. Nesse sentido, existe o direcionamento para a construção de uma consciência coletiva em torno da utilidade social do investimento financeiro, direcionado a uma matriz produtiva sustentável concebida sobre os princípios da Economia Solidária e da Agroecologia.

As atividades econômicas são exercidas como forma de geração de renda para os agricultores, entretanto não é a exclusiva busca pelo lucro que orienta suas ações, mas a intensificação das relações sociais, fortalecendo o capital social como instrumento para dinamizar os fluxos de informação e potencializar as ações rumo a objetivos compartilhados, como acesso a mercados e ampliação da capilaridade das organizações. É, por esta via, que o capital social orienta e regula a circulação do capital financeiro através das cooperativas de crédito.

O compartilhamento de ações econômicas, sociais e políticas vão tecendo a rede que alicerça a Ecosol e as organizações locais, dando forças à expansão da atuação dessas organizações e de suas ações para um nível macro. Como afirma Granovetter (1991), instituições econômicas estáveis resultaram de padrões de atividade em torno de redes sociais. Portanto essas ações contribuem para o desenvolvimento local na medida em que mobilizam capital social e viabilizam projetos dos agricultores familiares em Espera Feliz. O (des)envolvimento local sustentável parte dessa concepção política organizada e reproduzida pela agricultura familiar e se materializa nas ações e consequências explicitadas neste trabalho, como externalidades das interações entre organizações coletivas.

\section{Considerações finais}

As relações sinérgicas constituídas entre as organizações locais da agricultura familiar e a Ecosol na promoção de ações conjuntas orientadas para o desenvolvimento local se tornam importantes na medida em que vão consolidando bases sociais de cooperação, formando o tecido social no qual essas organizações se alicerçam, potencializando a mobilização de recursos, pessoas e ações para uma proposta compartilhada de transformação da realidade social e econômica da agricultura familiar. Esse capital social pode ser considerado, então, a chave explicativa da complexa trama de relações que sustenta e reproduz o arranjo organizacional da agricultura familiar em Espera Feliz.

Esse arranjo organizacional denota uma forma de organização social da agricultura familiar, que permite aos atores locais definir modos de coordenação e interação entre unidades organizacionais especializadas e funcio- 
nalmente diferenciadas. Esse argumento parte da constatação anterior de que, nas relações econômicas cotidianas que marcam as relações interorganizacionais, as organizações são precedidas por relações sociais. As redes sociais que sustentam as organizações da agricultura familiar são constituídas e constituintes do capital social que as operacionaliza.

A superação dos diversos desafios da organização focal analisada vai depender veementemente da cooperação, da solidariedade e da coesão social do arranjo do qual faz parte. Esses fatores devem ser mantidos e disseminados para a garantia de seus princípios e consolidação da rede organizacional que ampara a cooperativa de crédito. Os espaços institucionais constituídos contribuem para a perpetuação das relações interorganizacionais, e reafirmam a participação enquanto condição intrínseca ao aprendizado coletivo, instigando o sentido da capacidade de intervenção social dos atores locais.

Nesse contexto que estimula a cooperação, melhora-se o desempenho institucional em geral, e da cooperativa de forma muito particular. As redes sociais se tornam coletividades socialmente coesas, em que a frequência de interações econômicas e a densidade das relações sociais permitem à Ecosol reduzir incertezas ligadas ao crédito, possibilitando limitar comportamentos desonestos por meio de ações morais socialmente compartilhadas e padrões de conduta institucionalizados nas comunidades rurais. Dessa forma, a governança construída entre as organizações e a Ecosol possibilita a redução de assimetria de informação e de custos de transação embutidos nas intermediações financeiras realizadas pela cooperativa e corrobora com a sua sustentabilidade.

Esse capital social que emana da interação entre as organizações locais da agricultura familiar em Espera Feliz particulariza o processo de desenvolvimento local ao sublinhar seu conteúdo multidimensional e dinâmico. O desenvolvimento, marcado por esse envolvimento local, parte mesmo da premissa de que sua característica predominantemente endógena reforça o potencial de transformação que a sociedade civil organizada possui, nesse caso tratando da agricultura familiar. A Ecosol, como parte do arranjo organizacional local, compõe apenas uma peça do esquema, que precisa ser compreendido para decifrar a estrutura social que define o meio rural analisado.

\section{Referências}

ABRAMOVAY, Ricardo. A densa vida financeira das famílias pobres. In: ABRAMOVAY, R. (Org.) Laços financeiros na luta contra a pobreza. São Paulo: Ed. FAPESP/ Annablume, 2004.

ALTIERI, Michel A. Agroecologia: bases científicas para una agricultura sustentable. Montevideo: NordanComunidad, 1999.

BARDIN, Laurence. Análise de conteúdo. Lisboa: Edições Setenta, 2009.

BOURDIEU, Pierre. The forms of capital. In: RICHARDSON, J. G. Handbook of theory and research for the sociology of education. Nova York: Greenwood, 1986.

BUARQUE, Sérgio C. Construindo o desenvolvimento local: metodologia de planejamento. Rio de Janeiro: Garamond, 2002.

BÚRIGO, Fábio Luiz. Finanças e solidariedade: uma análise do cooperativismo de crédito rural solidário no Brasil. 2006. Tese (Doutorado) - Programa de Pós-Graduação em Sociologia Política, Universidade Federal de Santa Catarina, Florianópolis, 2006.

CAZELLA, Ademir Antônio; BÚRIGO, Fábio. Luiz. Inclusão financeira e desenvolvimento rural: a importância das organizações territoriais. Política e Sociedade, v. 14, p. 301-331, 2009.

COLEMAN, James S. Social capital in the creation of human capital. American Journal of Sociology, Chicago, v. 94, p. S95-S120, 1988. Supplement.

GAMBETTA, Diego (Ed.). Trust: making and breaking cooperative relations. Oxford: Basil Blackwell, 1988.

GRANOVETTER, Mark. A theoretical agenda for economic sociology. New York: Department of Sociology - Stanfod University, 2001.

. Economic Action and Social Structure: The Problem of Embeddedness. American Journal of Sociology, v. 91, n. 3, p. 481-510, 1985.

Economic Institutions as Social Constructions: a Framework for Analysis. Paper prepared for the CREA conference on 'The Economics of Conventions'. Paris, 1991.

MAGALHÃES, Reginaldo Sales. Planejamento de serviços financeiros para famílias de baixa renda. In: ABARAMOVAY, Ricardo (Org.). Laços financeiros na luta contra a pobreza. São Paulo: Annablume/Fapesp/ ADS-CUT/Sebrae, 2004.

MINISTÉRIO DO DESENVOLVIMENTO AGRÁRIO MDA. Plano territorial de cadeias de produção cooperativa: orientações metodológicas e operacionais para a elaboração. Brasília: MDA/SDT, 2007.

POLANYI, Karl. A grande transformação: as origens de nossa época. 2. ed. Rio de Janeiro: Elsevier, 2000.

PUTNAM, Robert. Comunidade e democracia - a experiência da Itália Moderna. Rio de Janeiro: Fundação Getúlio Vargas, 1996. 
SABOURIN, Erik. Organizações formais e dispositivos coletivos dos agricultores no Nordeste Semi-árido. In: SABOURIN, E. (Org.). Associativismo, cooperativismo e economia solidária no meio rural. Cadernos do CEAM, Brasília, n. 23, p. 51-93, 2006.

SACOMANO NETO, Mário; TRUZZI, Oswaldo Mário Serra. Sociologia econômica e governança: visão sociológica da ação nos mercados. 2008. Disponível em: <www.
dep.ufscar.br/grupos/nesefi/st/anais_st/eixoI/Mario_Sacomano.pdf $>$.

STEINER, Philippe. A sociologia econômica. São Paulo: Atlas, 2006.

WEBER, Max. Economia e sociedade. Brasília: Editora UNB, 1991.

YIN, Robert K. Estudo de caso: planejamento e métodos. 2. ed. Porto Alegre: Bookman, 2001. 